\title{
11. The Future of the Basin: Thriving or dying communities?
}

\author{
Chris Miller
}

The publication of the much-delayed Guide to the proposed Basin Plan by the Murray-Darling Basin Authority (MDBA 2010) should have seen it hailed as a landmark document. This was the opportunity to present for subsequent endorsement by the Commonwealth Government a robust basin-wide strategic plan, informed by the best available science. Such a plan would have secured the long-term environmental sustainability of this precious resource, ensured a sustainable future for irrigated agriculture - on which Australian food production depends - and offered the prospect of long-term sustainable livelihoods for basin communities, albeit a future with less water.

Instead, the publication of the Guide was met with howls of protest from irrigated-farming representatives and basin communities. The furore provoked an immediate loss of confidence by the MDBA in some critical aspects of its own work - notably, the socioeconomic data - and a declaration that further research was needed. This inexplicable retreat from the MDBA's own analysis led the Federal Government to question whether the Authority had met its legal obligations, seeking advice on the meaning of the Water Act 2007 in relation to the balance between environmental entitlements and community social and economic impacts. The Sydney Morning Herald editorial (22 October 2010) was moved to declare that Tony Burke, the Minister for Environment, Sustainability, Water and Community, was 'running scared' from the first signs of concerted opposition.

The growing tension between the Minister for Water and the Chair of the MDBA led to the latter's resignation and replacement. Simon Crean, the Minister for the Regions, also announced a separate six-month Parliamentary Inquiry into the Socio-Economic Impacts of Water Reform, chaired by the Independent MP Tony Windsor. Meanwhile, the Water Minister, Tony Burke, attempted to create some daylight between the 'independent' Guide and any subsequent government decision, with the minister quoted as saying, 'It is not my Guide'. It is a sure sign of how bad the process is when a federal minister disowns recommendations not yet presented to him in the form of a draft Basin Plan and before the formal public consultation process had even begun. This was also a risky strategy for the Government as such actions could be interpreted as too hasty a rejection of recommendations based on the 'best available science' from an independent body established by the Government specifically to undertake this task. All this 
occurred within the first three months of publishing the Guide. Rarely can a document of this magnitude have been so quickly undermined - an achievement even more striking given the genesis of the Basin Plan with its strong bipartisan support for the principles of reform. Despite relatively rigorous hydrological and environmental science, the insufficiently robust social-science data and analysis have proven to be the Guide's Achilles heel and threaten to derail its progress.

\section{A Reform of Complexity and Scale}

The MDBA was very conscious of the enormity of the task it had been given, noting that in relation to scale and complexity it could find no other comparable exercise worldwide. Faced with this challenge, the MDBA acknowledged that its ability to marshal and apply the best scientific knowledge available would be critical to a successful outcome. Thus, the Guide notes:

Planning of this scale and complexity has never been undertaken anywhere in the world. As a result it was important that the Authority brought together the best available data, modelling and scientific knowledge to support decision making...The independent reviews confirm that the approaches being taken...represent the best available (biophysical and social) science and knowledge...[but] there is much scope for further work and additional data capture into the future. (MDBA 2010:37)

The Guide makes clear the objectives of the Basin Plan in terms of ensuring the long-term management of the Basin's water resources, as 'redressing the degraded ecological health of the Basin while optimising the social, economic and environmental outcomes' (MDBA 2010:5) and providing 'a clear transition path for entitlement holders and communities through the period from plan adaptation to implementation at local level' (p. 7).

Unfortunately, the Authority has failed to live up to the requirements of a task that undoubtedly demanded some fortitude when confronted with predictably hostile interest groups. Instead, it was unable to provide a robust defence of its findings and proposals or to engage stakeholders in constructive debate. Indeed, the Chair began to give ground on the Authority's bottom line in sustainable diversion limits (SDLs) after a mere week of facing sometimes large, hostile and generally negative reaction from public consultation meetings that had attracted audiences of up to 5500 people. Anger and defiance from those most immediately affected by the proposals should have been anticipated, but questioning the validity of its own social-science data, especially the potential socioeconomic impacts of reform, only expanded the space in which outrage and criticism could flourish. 
This chapter is concerned with one area of major weakness in the Guide - namely, the lack of attention given to what it describes as 'mitigation strategies' and its failure to go beyond mere mitigation measures to enable those communities most affected by water reform to make long-term adaptations to ensure a sustainable future. The use of the concept of 'mitigation' reveals the poverty of the MDBA's thinking in relation to potential socioeconomic impacts. It is clearly not concerned with how communities might go about transforming and diversifying their local economies faced with a contracting irrigated-agriculture industry. Rather, its perspective is restricted to managing the scale of such impacts so as to arrive at some 'acceptable' level. It seeks only to leave basin communities much as they were - albeit in a diminished or depleted form. Further, even within the limited bounds of mitigation, the MDBA assumed irrigated agriculture to be a healthy industry prior to the requirements of water reform. In fact, there were some major structural fault lines in the industry evident long before the so-called millennium drought. In failing to identify these fault lines, any futureoriented proposals were going to fall well short of what is required. This chapter highlights both why this approach is a major weakness and how a failure to include a robust investment plan for the future of regional communities puts at risk the water-reform agenda. Finally, it offers an approach to transition that could yet provide the means by which to keep the reform process on track.

\section{The Place of Social and Economic Impacts in Water Reform}

The Guide makes clear that the Basin Plan must take cognisance of social and economic impacts whilst ensuring a sustainable environment. Thus, it notes: 'The Water Act 2007 requires that in meeting the additional environmental water needs...the Authority must optimise social, economic and environmental outcomes, and at a minimum, the impacts need to be well understood' (MDBA 2010:39).

Despite the not inconsiderable amount of social-science research commissioned in preparing the Guide, the MDBA concluded that this remains insufficient to enable it to make what it describes as finely tuned decisions even after it had sought additional advice from a range of sources. This overly cautious viewpoint is stated at numerous points throughout the Guide and is summarised thus: 'the existing social and economic evidence base... was not considered adequate to undertake the required assessment at a fine degree of resolution' (MDBA 2010:39); and again: 'Of the evidence available to the Authority, the social and economic evidence is the weakest' (p. 197). 
We are assured, however, that this assessment was reached only after extensive efforts. Thus, it notes:

To overcome the weakness...the Authority sought advice from industry, community and government stakeholders...commissioned a wide range of studies...Work to develop regional profiles was also undertaken and a comprehensive data store of available social and economic information was compiled...A synthesis of current knowledge of the concepts of community resilience was also undertaken...with an emphasis on understanding the drivers of change...economic modelling was undertaken...to estimate the direct impacts on agricultural industries of various scenarios of reductions in water availability...work to understand the effects of changes in water availability on Aboriginal communities... was undertaken by CSIRO. (MDBA 2010:39)

But in the final analysis, the MDBA (2010:197) is forced to conclude that it 'has been unable to identify any consistent social and economic data that allows analysis of the flow-through impacts beyond the farm gate to the broader local economy and social fabric of the Basin'.

The MDBA (2010:xxviii) is clear in its disappointment in the exactness of the current social-science database and its desire to see further comprehensive assessments undertaken at community and industry levels. Nevertheless, it remains confident in its judgment about the scale of these impacts on community sustainability. The Guide acknowledges that some of the work undertaken might not provide sufficient insight into what is a complex set of dynamic interactions at a community and industry level. Yet when combined, the evidence is said to provide a solid foundation for consideration of the socioeconomic issues relevant to determining a SDL regime (MDBA 2010:41): 'the studies' findings provide an understanding of the social and economic capacities of communities and improve information on the upper and lower bounds of likely effects' (p. 84).

Indeed, the Authority suggests that the socioeconomic impacts 'may be overstated as they do not take account of the potential for farming innovation that might increase yields' (p. 88).

Ironically, whatever the perceived shortcomings of the existing data, research published more than 10 years ago by Neil Barr from Victoria's Department of Natural Resources and Environment, using data for the period 1986-96, highlighted structural fault lines within irrigated agriculture, and agriculture more broadly, that have little to do with water reform. These include the declining numbers of farm establishments, farm families and farmers; the loss of young people from agriculture and from basin communities; the ageing profile of farmers; insufficient productivity gains for a majority of farms to compensate 
for the compression in terms of trade; low incomes amongst many farmers and increasing dependency on off-farm income; the loss of 'entrepreneurial' farmers with mid-sized farms through increased investment-driven debt and the high costs and risks associated with entry into agriculture. Had the MDBA explored these data, it might have been persuaded to further investigate the health of the industry. It might also have recognised the need to disentangle the socioeconomic impacts of water reform from the more deeply rooted structural issues confronting irrigated agriculture. Such an examination might also have drawn the MDBA to conclude that what was required was a thoroughgoing investment strategy for regional communities that took account of, but went beyond, specific water reform-related impacts.

More recent research (Grafton et al. 2010) reinforced the sense that basin communities already struggle with major structural problems of their own. The research identified higher than average suicide rates amongst farmers, growing referrals to mental health services well beyond the capacity of service providers, increasing levels of reported domestic violence and crippling levels of household debt. In addition, there was some evidence of a growing level of antisocial behaviour amongst young people and low levels of educational attainment. The recruitment and retention of essential professionals such as medical and healthcare workers, social workers and teachers are longstanding problems. Some communities are already showing signs of further decline as indicated by lower housing market values and closures within the retail and service sectors. There is evidence too of an outward migration of those with highly valued skills and expertise and without whom there will be only a limited and restricted future for some basin communities. There can be little merit in a Basin Plan that fails to address such core structural issues. There will be no future if young people cannot see a future in the Basin but continue to leave for the metropolitan areas. Irrigated farming will continue to be an unattractive option until the mental health of farmers and farming families is addressed.

There is no doubting that socioeconomic data at a community level could be strengthened. Equally, that communities with sufficiently diverse economies will be 'relatively resilient' so as to navigate the transition (MDBA 2010:xxi). Yet, it can also be assumed that for some communities in some catchments, the impacts will be severe, and the long-term survival of some smaller communities heavily dependent upon water-based industries might be at risk. Further, all communities faced with large reductions in irrigated water will be required to make major adjustments. Some will be faced with the transformation of their local economy. Such transformations are concerned not simply with the minimisation of job losses - important though that might be-but in reimagining quite different ways in which the community can generate wealth. 
Thus, the overall volume of total potential job losses as a consequence of reduced SDLs might be relatively small when viewed in a national context and could theoretically be absorbed in what continues to be a buoyant labour market, facing if anything a skills shortage and generating a job surplus. Yet such new employment opportunities do not always match the skill mix of those losing their jobs, nor are they always in the right locations, and people are not always in a position to relocate. In many regional communities, the impacts of job losses are likely to reverberate across the whole local economy. These are, after all, small, interdependent economies retaining a large proportion of locally generated income, and therefore big employment losses in a major industry such as irrigated agriculture will have real consequences for jobs in other sectors, including those not obviously dependent upon irrigated farming. Thus, the Guide notes that

[t]he agriculture industry in the MDB provides an annual average of $\$ 15$ b worth of produce to the national economy...Indirectly agricultural activity is also a key economic driver of local industries and regional activities that support small and medium enterprises and employment across the Basin. For example, around one-third of people employed in manufacturing are employed in food products industries, representing a further 30,000 employees. (MDBA 2010:21)

Further, it (MDBA 2010:96) points out that between 50 and 70 per cent of farm expenditure is in nearby towns, with a further 20-30 per cent in regional centres, estimating that more than 75 per cent of total farm expenditures are recycled back into the regional economies. Similarly, with some 65000 farms across the Basin, the Guide acknowledges the dependency of small and mediumsized businesses on agricultural revenues and irrigator expenditures, as well as the loss to the rateable base of local government services. These likely follow-on effects will have an impact on the overall level of confidence in the future of such communities, such that the skilled and mobile workers might relocate to seek better, more secure employment elsewhere, local investment capital might do likewise and external capital will be disinclined to invest. It is this type of logic that informs the MDBA in judging that it cannot go beyond a $4000 \mathrm{GL} / \mathrm{yr}$ SDL. Such assessments are, however, at best predictions based on what might happen if there are no other counter measures put in place. Such interventions could enable communities to plan for reform and transition towards a more diversified sustainable economy. 


\section{A Flawed Analysis}

It is difficult to see how the MDBA can justify paying so little attention to community transitional strategies. For those living with the prospect of reform, mitigation is the minimal response to an impact assessment. With sufficient advance warning and planned change, actions can be taken to remove or minimise the dependency on whatever is the source of the impact. The MDBA (2010:xiv) was indeed aware of the importance of such transitional arrangements, noting 'it is essential that effective transitional arrangements be put in place to help businesses and individual water entitlement holders adjust to change, and why action must continue to be taken to maintain strong and prosperous regional communities'.

Again, it highlights what it sees as a critical issue: 'Depending on the local communities' capacity to adapt...the short-term social and economic impacts on some communities and regions could be severe without structural adjustment... more and specific targeted assistance could be considered by government' (MDBA 2010:xxvii).

Yet despite such concern and acknowledgment that '[e]ffective transitional arrangements... will be essential', the MDBA (2010) offers only two very limited mechanisms - neither of which matches its own declared sense of urgency, plus some half-hearted reassurance:

The Water for the Future program is likely to affect the eventual impacts...by providing additional water savings...and by providing regional economic stimulus. (pp. 120-1)

For transitional or interim water resource plans that cease less than five years after the date of the Basin Plan being adopted...the Authority proposes that SDLs be phased in over a period of five years, allowing water users and communities more time to adjust to the new arrangements...

The Authority recognises that there will also be benefits that will flow through to communities because of improved environmental conditions. (p. 124)

Even by its own admission, the MDBA accepts that revenue from selling water entitlements might not recirculate through local communities but could instead be used to discharge debt, to which one might add relocation, retirement or inheritance gifts. What we are left with is a series of assertions that are either insufficiently developed or unsubstantiated. First, we are told the data on the social and economic impacts could be improved. Next, we are informed that transitional arrangements are critical in determining actual impacts but little is 
offered by way of such interventions. Finally, despite reservations over the data, no consideration can be given to water reductions of more than $4000 \mathrm{GL} / \mathrm{yr}$ due to the apparently unreliable predicated impacts. Thus, it states: 'The Authority recognises that there is no formula for determining the optimal result and will do this by applying its judgement' (MDBA 2010:107).

Also, 'the Authority has made a number of critical judgements...reductions that exceed 4,000GL/y ... would not represent an optimisation of the economic, social and environmental outcomes under the Water Act' (p. xxi).

There is indeed no formula but there are processes available that better determine the outcomes. The MDBA is, however, unable to argue this point with any real conviction, and indeed the whole chapter in the Guide on socioeconomic impacts is scattered with conditional statements with plenty of 'mights', 'coulds' and 'maybes'. The crucial role given to 'judgment' in making determinations for the social and economic impacts stands in sharp contrast with the emphasis given to peer-reviewed science in the determination of the SDLs. The MDBA (2010:81) is aware of the shortcomings in its analysis, noting: 'This chapter does not include analysis of the potential contribution to mitigation measures. The impacts presented in this chapter are likely to be larger than the final impacts.'

In adopting an approach that ignores the potential for regional development via transformational strategies, the MDBA exposed itself to avoidable criticism. It was immediately required to defend itself from farming and irrigation industry organisations in particular but also from many angry farmers, growers and community members about the veracity of its analysis.

\section{The Response to Social and Economic Impacts}

Despite its own lack of confidence in the data, especially its capacity to address community-specific impacts, the MDBA does offer some aggregate assessments. Thus, it notes that

[r]egions with a relatively higher dependence on lower-value irrigated agriculture would experience a larger reduction in economic activity. The social fabric of some towns and communities may be significantly affected, particularly in the near term. The capacity of towns to adapt is likely to vary widely, and would be influenced by factors such as the size of the community, the diversity of its economic base, its demographic mix and its proximity to other large regional towns. Some communities may be permanently changed by the reduction in diversion limits. (MDBA 2010:81) 
Part of the problem, however, is not in the availability of data but in the capacity of the MDBA to both analyse data and identify relevant types of available data. For example, in determining relative community success in adaptation to reduced water (MDBA 2010:xxxiii), the primary focus is on water-related indicators to the exclusion of other equally important signposts such as the minimisation of long-term job losses, the level and speed of job replacement, the maximum number of communities retaining current levels of or growth in population, producing an equivalent contribution to regional/national economies, community capacity to retain young people and retaining those 'pull' factors to attract new migrants, and so on. It is the failure to explore the range of available transitional arrangements that leads the MDBA to perhaps its most important decision to restrict consideration of water diversions to 4000 GL/yr. Thus, it argues:

In light of the severity of this impact on specific sectors and communities the Authority has judged that...it can only consider Basin-wide reductions of between 3,000-4,000 GL/y for the Basin...reductions in current diversions above 4,000 GL/y have been judged to be beyond the range of acceptable reductions. (MDBA 2010:82)

The judgment is based on data that suggest a decline in gross value of irrigated agricultural production of about $13-17$ per cent or \$0.8-1.1 billion per year, or between 1.1 per cent and 1.5 per cent reductions in permanent long-term regional production (MDBA 2010:120). No account is taken of the potential for this lost value to be ameliorated by equivalent or greater gains in other parts of the Basin economy, either by developing existing industries or through the introduction of new products and services. In other words, this is a judgment made only on the basis of the impacts of reducing irrigated agriculture and an assumption that there will be no new economic development. The failure to plan for such change will only increase the likelihood of this scenario being realised. Thus, the role of 'judgment' becomes central to social and economic impacts, in contrast with the role of science in respect of environmental requirements.

One explanation for the MDBA's failure to consider transitional strategies lies perhaps in its equally flawed claim that change is driven by the actions of multiple individuals acting independently. Thus, the MDBA (2010:83) asserts that 'economic and community change is driven by the adjustment decisions of individuals. In response to a reduction in diversions, it is irrigators' decisions that will drive change in communities where irrigated agriculture is a large part of the economy.'

Whilst it is true that individuals will indeed make decisions and in doing so will take account of a range of factors, the context or framework in which those decisions are taken is determined by more powerful forces, such as 
government, national and global corporations, the financial services sector and global markets. Indeed, the Plan itself is an obvious example of governments generating change. Again, the MDBA (2010:xiv) appears to have chosen to ignore its own assessment that previous government interventions have been critical in shaping the conditions of today:

The Basin and its communities are facing significant challenges and risks...the direct result of the actions of successive governments over the history of the Basin...failed to strike a balance between meeting the needs of the environment and those of a growing economy and population...

Many towns in the Basin have grown throughout many years of government policy that encouraged water use and regional development. (p. 82)

In making this rather limited assertion that individuals are the ones in the driver's seat of change, the MDBA can claim that as it is unable to predict how so many diverse individuals will behave there is little point in dwelling on this aspect. Had it followed the logic of its assessment that there are other more influential forces at work in creating the conditions in which individuals act, and the importance of government in this process, it would have considered the range of transitional strategies adopted elsewhere, supported by governments and global agencies such as the United Nations, and evaluated the outcomes. Instead there is an extraordinary absence of any applied social science in the Guide despite an apparent awareness of the limitations of its own proposed transitional arrangements: 'These transitional arrangements in themselves may not be sufficient and action may be needed by all levels of government to maintain prosperous, resilient regional communities' (MDBA 2010:xx).

The Authority further compounds the problem by demonstrating its own inability to construct good social-science analysis. There is evidence of this in its justification not to explore impacts in more detail by attempting to categorise the diversity within the farming sector (MDBA 2010:88). We are offered six somewhat dubious categories or farming 'types'. Thus, it is suggested that one type of farmer is one who is 'concerned and uncertain about the future of irrigated and dryland agriculture in the Basin'. Now it might be the case that there are indeed still farmers who are unconcerned and certain about the future following the worst droughts on record, but one would hope that these are few in number and would probably be better off in some other line of work.

Next, we are offered those who are well prepared for lower water entitlements against those who are not; those who are optimistic and/or have strong connections with the community against those who are pessimistic and have 
weak connections; those who are close to retirement and those who are younger; those who are financially stable and those financially exposed due to the extended drought and surviving on exceptional circumstances payments and off-farm income. Such categories are, however, awash with flawed argument. It is, for example, erroneous to suggest that high off-farm income somehow makes for financial insecurity. Rather, the opposite could be the case. With secure offfarm income, households can make better decisions and better manage inherent farming turbulence. Equally, it is not at all clear why a personal characteristic such as optimism should be lumped together with strong community or farm connections. These are unrelated, as connectivity is relational and dynamic and speaks as much to something desired as to something already achieved. It might also reflect something that was once strong and important but has been weakened and is no longer important. Nor is it necessarily one or the otherstrong or weak - but is in fact a relative state.

Further, although the meanings are not explained, to have strong community connections is probably something the MDBA thinks of in terms of intergenerational longevity, and indeed this might have been a better category to adopt. The main point is, however, that this does not reflect a 'type' of farmer (there might be some farmers who do not have and do not want to have strong community connections), but rather it describes both an existing relationship and something that can be altered. These are not types of farmers but rather in the main they describe different sets of circumstances in which farmers might sometimes find themselves.

One factor that cannot be altered is that of age. So a better starting point of analysis would be to consider those who are close to retirement and those who are relatively young farmers. In each of these categories, the extent to which someone is financially secure and efficient will make a difference to how they decide on a future direction. Other more useful categories might relate to the size of farm or the nature and diversity of production. In other words, the categories of farming types identified by the MDBA do indeed convey a sense in which it is difficult to envisage a rational policy response, given such muddled categories that do not lend themselves to analysis.

\section{Community Transitional Strategies}

One of the weaknesses in using only a set of social and economic assessment indicators is that, while useful as a predictive tool that provides stakeholders with an opportunity to consider the potential repercussions of any impending change, they are less robust in anticipating how people might act. Increasingly, it is recognised that identifying such indicators cannot rely simply on objective 
criteria determined outside the community but must engage the communities in shaping the data (Young et al. 2002), and that any criteria should be open to scrutiny and revision through community dialogue.

Other models are also available, including the 'Sustainable Livelihoods' approach (Scoones 1998) that is popular in the context of international development (Brocklesby and Fisher 2003). It has been adopted by various governmentsincluding in the United Kingdom, and some Canadian Provinces, notably British Columbia and Quebec (Markey et al. 2009) — and is recognised by the UN International Fund for Agricultural Development. The UK Department for International Development (DFID 1999:1) suggests that the frameworkwhich is to be applied in a participatory manner - is to 'help stakeholders with different perspectives to engage in structured and coherent debate about the many factors that affect livelihoods, their relative importance and the way in which they interact' in order to identify 'appropriate entry points for support of livelihoods'.

A third, albeit derivative, approach is that of an 'Adaptive Capacity Index' (Stenekes et al. 2010), which requires, according to Nelson et al. (2007:iv), 'the continual process of inventing, adapting and adopting...to anticipate and respond to change'. Rather than focusing on impacts and responses that might mitigate the worst of these, the Adaptive Capacity Index plays to the potential for agency and creative change. It gives emphasis to the opportunities within any situation, however undesirable, and our emergent capacity to respond to stress (Sietchiping 2006). As with all theories that prioritise agency, it is useful to also take account of potential barriers to adaptation, or what might explain people's failure to exploit these capacities. Finally, recent attention has focused on the concept of community resilience that again is focused on community resources and adaptive capacities (Maguire and Cartwright 2008).

Rather than explore the potential application of these well-respected approaches, the MDBA opted for a narrow, economically driven model of adaptation. Thus, it draws upon work undertaken by Frontier Economics (2010) to highlight five aspects of what it refers to as 'adjustment pressures'. These are: market, social, technological, government policy and environmental pressures. Such factors are, however, not felt simply as pressures to adjust, as they can both shape and channel the direction of adjustment, as well as blocking off certain avenues. This is a particularly important consideration when we examine what individuals might take into consideration when making a decision.

The Guide - again, drawing from the same source - is focused most extensively on business-related factors, such as expected profitability, outlook, financial position, business objectives, risk aversion, understanding and uncertainty, and strategic behaviour whilst also including 'perceptions, attitudes and ethics'. 
This ignores other potentially influential factors, including commitment to community and place, investment in future generations, lifestyle, position in the life cycle and opportunities to move into new areas of expanding economic activity. The MDBA locates the influence of 'alternative economic opportunities' in a box designed to show how the severity of impacts will vary alongside the 'extent of aggregate/cumulative adjustments' made by individuals. In other words, the adopted model has individuals acting as purely rational economic planners who make decisions in the context of a number of adjustment pressures. The cumulative effect of such individual decisions is what is assumed will motivate industry-level structural change and this is then offset in terms of its severity by a number of other factors, including the potential for alternative opportunities and a community's capacity to respond to change.

In reality, life is more complex, messy and dynamic than this suggests. Individual decisions are not made solely on economic grounds, nor are they always 'rational'. Decisions about a specific industry are not made in isolation or without reference to wider economic and non-economic considerations both actual and potential. For example, much is made in explaining the behaviour of national and global markets of the role of 'market confidence', and there is no reason to suspect that this is less so at a local level. Yet confidence in current and future prospects is intangible and multidimensional, and includes emotional states of mind. At a local level, it is difficult for any community to sustain a sense of self-confidence and optimism when faced with what feels like overwhelming negative external pressure on a core industry - a sector that defines its identity as well as sustaining its economy. Optimism in the future is especially difficult to sustain in a context in which a community has only just emerged from what has been the worst drought in recorded history. In such circumstances, communities need the reassurance of government and might also need some external intervention to enable them to rebuild community resilience and adaptive capacities. Such circumstances highlight the importance of early intervention transitional strategies in anticipation of major social and economic impacts following policy reform. The MDBA is not unaware of such complexities, stating:

[T] he Authority recognised the range of complex and inter-related factors that will exert influence on the ultimate outcome...

The short-term economic effects... depend on the particular circumstances of the Basin's businesses and individuals and their capacities to adapt... they will respond in different ways to the transitional support that is provided to enable Basin communities to adjust. (MDBA 2010:94) 
An evaluation of transitional strategies practised elsewhere-designed in response to predicted social and economic impacts and to enable communities to make adjustments to ensure future sustainable livelihoods - would have led to a far greater range of options than what is offered in the Guide. Such considerations are well within the remit of the MDBA, charged as it is with securing environmental sustainability whilst optimising social and economic outcomes. Instead, the Authority walks away from this responsibility, handing it to others - namely, State and Federal governments - and in doing so appears to reduce the problem to the mere provision of social facilities. Thus:

The success with which communities transition will be shaped by the continued provision of community services... and the on-going activities of community clubs, sporting clubs and other community connections. Sustaining the social fabric of communities will be in part determined by the economic adjustments... and the strength of communities' social capital will in turn also shape communities' ongoing economic success... the Authority has put significant weight on the policy settings of Basin governments as a critical determinant of the long-term future of Basin communities. (MDBA 2010:159)

The Authority cannot have it both ways. Either it treats seriously its requirement to optimise the social and economic outcomes of basin communities or it declares that this is beyond its brief or capacity. If it is part of its brief then it is responsible for a thoroughgoing analysis of both social and economic data but also of those strategies that enable communities to move forward when faced with major change. Anything less than this is a failure to fulfil its responsibilities. More importantly, it produces only a partial representation of what is a complex public concern, leaving critical options unexplored and generating unsubstantiated and inadequate recommendations that do an injustice to those communities most affected by water reform.

Rather than assisting in the process of adaptation and adjustment, the adopted approach is likely only to further exacerbate the social and economic impacts as communities experience prolonged and gradual decline, removing any sense of urgency and leading to a gradual exit from the community of human, social and financial capital. In contrast, the introduction of a community-adjustment strategy, referred to here as the 'Thriving Communities model', could provide a framework to enable communities to make the transition not simply by coping with social and economic impacts but by identifying a sustainable future for the communities of the Basin. 


\section{Thriving Communities Model ${ }^{1}$}

In outlining this approach to adaptation, it is first of all important to remember that it is not the first time that basin communities - in the context of nation building - have been called upon to plan for the future. For example, in 1945, the Australian Broadcasting Commission (now Corporation, ABC) produced a pamphlet in response to its radio program series entitled Communities Can Do It-Make a plan, calling on basin and regional communities to work together to identify local needs and build communities for the future.

Well before the publication of the Guide to the proposed Basin Plan, basin communities had been actively discussing how to live with less water. Local initiatives have sprung up to act on emergent ideas, although such actions have been small scale, localised and dispersed. The Guide makes no reference to such endeavours so any outcomes are not factored into the equation. Further, it is important to acknowledge that basin communities are diverse and complex so that there is not one but many stories to tell about what are the critical issues facing a particular community. Not only are there multiple perspectives and interests, some will be in conflict or tension with those of others. While some interest groups are well organised and resourced, confident and articulate, others will not be, and many will have remained silent, dispersed or excluded from the discussion. Even amongst the well-organised interest groups there is not a single voice or standpoint, although minority perspectives might have found it hard to be heard. This is especially so when people are represented by formal organisations. Again, based upon recent research (Grafton et al. 2010), there is substantial evidence that the resilience and adaptive capacity of basin communities have been greatly diminished by having to cope with 10 years of extreme dry conditions. The research also showed that there are currently in some parts of the Basin very low levels of trust in relation to government and to the MDBA in particular.

There is also an overwhelming sense in which the knowledge, skill experience, know-how and capacities of basin communities have not been recognised or respected and their views and perspectives have not been sought or heard. This failure to draw upon the wealth of knowledge in the Basin - to place it alongside expert scientific knowledge - is not simply a technical deficiency but will impede the implementation of any transitional strategy that ultimately depends on trust and collaboration between communities and government. Again, the research highlighted what might be described as a withdrawal from public affairs, with fewer people volunteering and low levels of participation in public meetings. In

1 An earlier version of the Thriving Communities Model was developed in conjunction with my Flinders University colleague Fiona Verity. It was first presented in Wentworth Group of Concerned Scientists et al. (2010). 
other words, the current levels of human, social and cultural capital within the Basin - critical in any change process - are yet another element missing from the assessment of social and economic impacts.

Any adaptation model has first to accept water reform as a whole-of-community issue and must involve previously excluded groups, such as young people, new migrants, women and Indigenous people. Second, community adaptation cannot be left to the vagaries of multiple individual decisions, but requires extensive community engagement over a sustained period, which acknowledges community specificity and provides for the maximisation of community control over the determination of its future. Despite differences within communities, there is evidence of a shared goal of securing a sustainable future with less water - a goal that brings together the concepts of growth and development. The objectives of any such adaptation strategy could be expected to include

- retention of local capital

- attraction of new capital investment

- fostering of the development of new products and services for a more diversified economy

- extension of community ownership of local services and enterprises

- encouragement of new migration

- retention of young people

- building human, social and cultural capital

- collaboration with other basin communities

- partnerships with local, State and Federal governments

- integration with local natural-resource management.

Government can be expected to play a critical role in the success of such an approach in at least five critical aspects. Key to this would be the creation of an investment fund for the future of basin communities to be allocated initially to those catchments most affected by the new SDLs, with the amount per catchment to reflect the percentage of water required for the environment.

Next, government needs to make available expert technical advice, especially in relation to developing new business opportunities. The emerging regional development agencies could provide the vehicle for such advice-although better still, communities could be given the opportunity to identify what they thought would be the most appropriate institutional structure. The key point, however, would be to ensure that the advice was provided by those who had firsthand experience in whatever was the field of knowledge. This could be ensured through a program of 'community secondments' from the business and financial sectors. 
Third - and again, critical to the success of any adaptation strategy - would be the appointment of a Basin Task Force to work within and alongside those basin communities most badly affected. Faced with a reform of this magnitude and given the specificity of basin communities and the diversity within, as well as between, them, highly skilled development practitioners are essential in bringing together and navigating this whole-of-community approach. A reform of national significance that seeks to redress previous government policies with major implications for regional Australia justifies the mobilisation of the most experienced and skilled workers able to work with such complexity and uncertainty.

Next, the Federal Government would be expected to work in partnership with basin communities as well as State and local governments, and new time-limited structures might be required specifically for this purpose. Finally, government would be responsible for mapping out the framework, the principles, structures and governance arrangements essential for the management of such a way forward.

The establishment of an investment fund is not a request for new or additional funds, but rather for a review and reallocation of monies already set aside for rural development and water reform. In particular there is a need to review the $\$ 5.8$ billion currently available for irrigation infrastructure improvements under the Water for the Future program. While the Federal Government is already committed in principle to State governments to about $\$ 3.1$ billion worth of projects, few of these are at an advanced stage of development and none has as yet been given final approval. There are at least three reasons why we need to revisit these earlier decisions in the light of the Guide.

First, many basin farmers and growers say themselves that they are already highly efficient, having invested heavily using their own resources during the drought. They would not have access to these funds that somewhat perversely would benefit those so-called industry laggards who might not deserve such a subsidy. Second, we now know that infrastructure projects of this nature are inefficient in securing additional water and that buybacks are a cheaper option. Indeed the Treasury in its 'red book' to the incoming government advised that such investment should be avoided except where it can be shown that the public benefit is greater than that secured through water buybacks. Third, time has passed since these decisions were taken and we are now more aware of the need to ensure the long-term sustainability of basin communities so we need a broader definition of what is understood by 'infrastructure investments'. In redefining the purposes of support, further improvements to irrigation infrastructure would not be excluded where that can be shown to generate a good return. 
To what purposes might such an investment fund be used? Keeping in mind the objectives outlined above, there are many possible areas for investment, including the following: the design and testing of new products and services, including drawing up business plans and marketing strategies; the creation of rural laboratories for the development of innovative solutions; supporting individuals with scholarships for tertiary education or training; the development of arts, cultural and heritage projects; the extension of the community-service sector including education, health care, social care and libraries; support for local community initiatives; investment in connectivity infrastructure, including road, rail and air services but also telecommunications. Similarly, a number of mechanisms are available in allocating the funds including small development grants, low-interest loans, co-investment with local private capital in venture-capital projects, and direct investment in community-owned local resources including property, industry and facilities. Regardless of the nature of the investment or the chosen mechanism, all projects seeking support would be required to meet viability benchmarks against a triple bottom line of economic, social and environmental sustainability.

Basin communities must be at the heart of any adaptation strategy. Maximum community engagement, along with community control, with all the uncertainties and messiness implied, in determining as far as possible its future direction is the key to any successful adaptation approach (Pepperdine 2000). The role of communities is to determine the local structures that will work best for them rather than being expected to accommodate structures that have been imposed upon them. Such structures would, however, be expected to ensure maximum participation and deliberation across the community, including previously excluded groups. Structures would need to be not only accessible but also transparent in decision making, accountable both to the community and to government, and genuinely community owned. Communities would be expected to mobilise local leadership and facilitate the emergence of new leadership capacities, linking up across the Basin into what might be described as a basin-wide Community Leaders' Forum to ensure mutual learning and enhanced strategic decision making. Communities would be expected to bring together local knowledge, know-how and experience to be placed alongside expert scientific, environmental and social-science impact knowledge. The combination of such knowledge and the identification of market opportunities provide the basis on which to generate Local Adjustment Action Plans that would shape the allocation of the Investment Fund. As with any rigorous change model, Thriving Communities would be underpinned by ongoing action-oriented research to ensure that the learning can be iterative and that past practice is shared with other basin communities. 
The model outlined here works from within communities. It adopts an integrated approach that works towards achieving sustainable livelihoods but begins with current and potential adaptive capacities and therefore with the history of those communities. Armed with the best scientific knowledge, it aims to build a platform for shared knowledge that includes local knowledge. The latter will provide critical accounts of community history, will cast light on the fine detail of local context, reveal current relationships, concerns and possibilities and identify resources for change. This is the work of the Task Force.

All this is vital if any community change and adaptation process is to succeed. The approach seeks to identify shared interests but is alive to the unequal distribution of impacts and unfair outcomes and acknowledges community diversity, differentiation and conflict. It affirms and works from existing community assets to further build local capacities and to strengthen community resilience. In pursuing these objectives, it seeks maximum participation in decision making through deliberative dialogues. A helpful metaphor for such deliberative dialogues is that of the kitchen table. Not only does this indicate the number of people that can comfortably engage in the process, it evokes that sense of an unfolding dialogue as people join the discussion for a period and then leave to do something else before returning. The time away from the table is an opportunity for reflection, a time that allows one to return having learnt something as a result and possibly modified one's standpoint. But the kitchen table also evokes that feeling of conviviality, care for those present and a desire to understand their perspective; it is the place where we prepare and share food together. Such cross-community kitchen-table dialogues need then to be joined together in larger community forums.

Would such a model work in practice? For there to be any hope of success, some preconditions would be necessary. Governments must first recognise and demonstrate respect for community knowledge, know-how, ideas, creativity and capacities. Governments need also to trust communities to deliver sound outcomes and must devote substantial resources to the task. In addition, all those involved need to be committed to finding more effective ways of talking with each other about complex issues in uncertain times. There are, however, no magic bullets, no short-term fixes.

What is required is long-term, sustained and incremental investment in rural futures. It needs to be built upon a vision for development that creates a framework of confidence in the future. It needs to deliver realistic and comprehensive plans for economic restructuring. Critically, such a model needs to be institutionally embedded. 
Examples from elsewhere can provide confidence in such an approach. For a comprehensive regional policy, that of Quebec's National Rural Policy ( <www. mamr.gouv.qc.ca $>$ ) offers a good starting point. For an example of more local practices in circumstances similar to the Basin, the Canadian Province of British Columbia (BC 2004) has for more than 30 years invested in regional trusts, as a key vehicle is regional social and economic development. For example, the Columbia Basin Trust, established in 1994, received a C\$295 million endowment from the Province plus an additional C $\$ 2$ million a year over 16 years, C\$45 million of which is used as an investment fund for community benefit. The Community Futures Program (<www.communityfutures.ca $>$ ), with more than 90 initiatives across the Provinces of British Columbia, Alberta, Saskatchewan and Manitoba, has been running since the mid 1980s. British Columbia has some 34 Community Futures programs, which, during the period 1995-2010, issued a total of 11442 loans, worth C\$330.8 million, which leveraged in another $\mathrm{C} \$ 618.9$ million and created 44680 jobs - an average of just less than 3000 per year. Whilst this does not tell us about the nature of such jobs or how many jobs were lost during that same period or what might have happened without the program in place, it nevertheless demonstrates that such local investments can be an important source of economic and social rejuvenation.

More than two million people live and work in the Murray-Darling Basin and it is home to many thriving communities that are critical to Australia's food production. The Basin is also facing an environmental crisis that demands fundamental changes to the way we manage and use natural resources. In making the required transition, the challenge is how to optimise social and economic outcomes by ensuring thriving and sustainable communities into the future. An approach such as the one outlined here provides an opportunity to secure this result.

\section{References}

British Columbia (BC) 2004, The BC Heartlands Economic Strategy: A place to revitalize our entire economy, Province of British Columbia, Victoria.

Brocklesby, M. and Fisher, E. 2003, 'Community development in sustainable livelihoods approaches: an introduction', Community Development Journal, vol. 38, no. 3 (July), pp. 181-98.

Department for International Development (DFID) 1999, Sustainable Livelihoods Guidance Sheets 1, Department for International Development, London.

Frontier Economics 2010, Structural Adjustment Pressures Affecting Irrigated Agriculture in the Murray-Darling Basin, Murray-Darling Basin Authority, Canberra. 
Grafton, Q., Miller, C., Duvnjak, A., Jared, D., Jiang, Q., Nikolakis, W., Ryan, P., Verity, F., Ward, P. and Zutshi, M. 2010, Potential Water Quality and Quantity Impacts in the Murray-Darling Basin from Communities and Industry Responding to Climate Change, Murray-Darling Basin Authority, Canberra.

Maguire, B. and Cartwright, S. 2008, 'Assessing a community's capacity to manage change: A resilience approach to social assessment, Bureau of Rural Sciences, Canberra.

Markey, S., Halseth, G. and Mason, D. 2009, 'Contradictions in hinterland development: challenging the local development ideal in northern British Columbia', Community Development Journal, vol. 44, no. 2 (April), pp. 209-29.

Murray-Darling Basin Authority (MDBA) 2010, Guide to the proposed Basin Plan. Volume 1: Overview, Murray-Darling Basin Authority, Canberra.

Nelson, R., Brown, P., Darbas, T., Kokic, P. and Cody, K. 2007, The potential to map the adaptive capacity of Australian land managers for NRM policy using ABS data, CSE49, 2007, National Land and Water Resources Audit, Canberra.

Pepperdine, S. 2000, Social Indicators of Rural Community Sustainability: An example from the Woady Yaloak catchment, Department of Geography and Environmental Studies, The University of Melbourne, Vic.

Scoones, I. 1998, Sustainable rural livelihoods: a framework for analysis, IDS Working Paper 72, International Development Studies, University of Sussex, Brighton.

Sietchiping, R. 2006, 'Applying an index of adaptive capacity to climate change in north-western Victoria, Australia', Applied GIS, vol. 2, no. 3 (16.1-16.28).

Stenekes, N., Kancans, R., Stayner, R., Reeve, I. and Coleman, M. 2010, Indicators of Community Vulnerability and Adaptive Capacity Across the Murray-Darling Basin-A focus on irrigation in agriculture, Australian Bureau of Rural Sciences and Institute for Rural Futures, University of New England, Canberra.

Wentworth Group of Concerned Scientists in association with Grafton, Q., Kowalick, I., Miller, C., Stubbs, T., Verity, F. and Walker, K. 2010, Sustainable Diversions in the Murray-Darling Basin: An analysis of the option for achieving a sustainable diversion limit in the Murray-Darling Basin, Wentworth Group of Concerned Scientists, Sydney.

Young, M., Young, D., Hamiliton, A. and Bright, M. 2002, A preliminary assessment of the economic and social implications of environmental flow scenarios for the Murray River system: a report prepared for the Murray Darling Basin Commission, July, CSIRO Land and Water Policy and Economic Research Unit and PIRSA Rural Solutions, Canberra. 